purchasers might consider "buying" inadequately evaluated therapies, on the same basis that physiotherapy was derided for accepting electrotherapy by “... giving credence to unscientific hype". ${ }^{1}$ Caveat emptor.

I fully endorse the author's call for more research into the efficacy of physiotherapy, and already many of the obstacles that impeded physiotherapy research are being addressed. In a recent letter in the British fournal of Rheumatology $5^{5}$ I explained that through the creation of university departments, the expertise and career structure exists to enable us to advance research in physiotherapy. We are now successfully competing for funding to critically evaluate our treatments, so that we can deliver the most effective treatment to our patients with the optimal use of resources.

MICHAEL V HURLEY
Physiotherapy Group
King's College
London
United Kingdom

Haslock I. Evaluating new physical treatments. Ann Rheum Dis 1993; 52: 607-98.

2 Heussler J K, Hinchley G, Margiotta E, et al. A double blind randomised trial of low power laser treatment in rheumatoid arthritis. $A n n$ Rheum Dis 1993; 52: 703-6.

3 Meade T W, Dyer S, Browne W, Townsend J, Frank A O. Low back pain of mechanica origin: randomised comparison of chiropractic and hospital outpatien treatment. BMF 1990; 300: 1431-7.

4 Correspondence ( 9 letters). Low back pain comparison of chiropractic and hospital outpatient treatment. BMF 1990; 300: outpatien

5 Wells P E. Manipulative treatment of the spine. Brit f Rheum 1993; 32: 179-80.

6 Sweetman B J. Hospital treatment for low back pain (Letter). Brit $\mathcal{f}$ Rheum 1993; 32: 854.

7 Hurley M V. The way forward for hydrotherapy (Letter). Brit $\mathcal{F}$ Rheum 1994; 30: 102

AUTHOR's REPLY: I am delighted that Dr Hurley agrees with me that much physiotherapy requires proper evaluation. This does not, however, imply repeating experiments indefinitely until the answer the researcher wishes has been obtained. One well conducted piece of research may well be all that is necessary to answer a question, and at the very least it requires an equally scientific reply rather than prejudice hidden behind words such as "measured judgments".

Had Dr Hurley read my editorial carefully he would have realised that I nowhere advocated the use of massage. He must accept, though, that massage and other complementary therapies are already high on the list of purchasers' wishes. A recent survey by the National Association of Health Authorities and Trusts showed that $65 \%$ of District Health Authorities and $70 \%$ of
Family Health Services Authorities favoured purchasing such therapies as part of their NHS provision. ${ }^{1}$ Probably many of them act only by a placebo effect, but few are likely to be purchased if they advocate, as Dr Hurley does for physiotherapy, the use of complex pieces of electrical equipment such as lasers as placebos.

IAN HASLOCK Department of Rheumatology South Cleveland Hospita Marton Road, Middlesbrough Cleveland TS $4 B W$
United Kingdom

1 Complementary Therapies in the NHS. National Association of Health Authorities and Trusts, 1993.

\section{Distinction between initiation and progression of the osteoarthritis process}

I read with positive interest but negative feelings the article by Cumming et al. ${ }^{1}$

Their conclusion that osteoarthritis of the hip should be included in the list of factors that protect against hip fracture, is in line with our previous observation on the inverse relationship between osteoarthritis and osteoporosis, ${ }^{23}$ and in particular with the recent epidemiological evidence revealed in the MEDOS Study. ${ }^{4}$ The MEDOS study is also based on self-reported osteoarthritis in a large series of controls and hip fracture cases. In both studies the inverse relationship between osteoarthritis and osteoporosis is independent of body weight, which supports the hypothesis that there is a direct causal relationship between osteoporosis and osteoarthritis.

A disturbing element in the paper by Cumming and Klineberg is the confusing terminology used throughout the paper. The term 'arthritis' is used interchangeably with 'osteoarthritis'. We do not agree that this interchangeable terminology should be used in an international rheumatology journal. The term arthritis is so bound to many other forms of arthritis, in particular rheumatoid arthritis, gout and pelvispondylitis, that this will inevitably lead to confusion in later citations. Although the term osteoarthritis is also not the best one, this term is now well accepted as an alternative to osteoarthrosis. According to our opinion and to many others, such as, Radin, ${ }^{5}$ clear distinction should be made between initiation of the osteoarthritis process and progression. That secondary inflammation might be involved in the progression of osteoarthrosis is well accepted, but whether inflammation is the primary trigger of osteoarthritis is doubtful. A number of studies on the initiation of the osteoarthrosis process support the possibility that the increased bone density reduces the mechanical ability of subchondral bone to deform under impact loads with resulting damage to the articular cartilage and osteoarthritis. ${ }^{67}$ J DEQUEKER
R WESTHOVENS

Arthritis and Metabolic Bone Disease Research Unit $K U$ Leuven, $U Z$ Pellenberg B-3212 Pellenberg, Belgium

1 Cumming R G, Klineberg R J. Epidemiological study of the relation between arthritis of the hip and hip fractures. Ann Rheum Dis 1993; 52: 707-10.

2 Dequeker J, Goris P, Uytterhoeven R. Osteoporosis and osteoarthritis (osteoarthrosis): Anthropometric distinctions. $\mathscr{f} A M A$ 1983; 249: 1448-451.

3 Dequeker J. The relationship between osteoporosis and osteoarthritis. Clin Rheum osteoporosis and osteoa

4 Dequeker J, Johnell O, and the MEDOS Study Group. Osteoarthritis protects against femoral neck fracture: the MEDOS study experience. Bone 1993; 14: S51-6.

5 Radin EL. Mechanical factors in the causation of osteoarthritis. Rheumatology. Basel: Karger, 1982: 46-52.

6 Gevers G, Dequeker J, Geusens P, NyssenBehets C, Dhem A. Physical and histomorphological characteristics of iliac crest bone differ according to grade of osteoarthritis at the hand. Bone 1989; 10: 173-8.

7 Gevers G, Dequeker J, Martens M, Van Audekercke R. Biomechanical characteristics of iliac crest bone in elderly women, according to osteoarthritis grade at the hand joints. I Rheumatol 1989; 16: 660-3.

AUTHORS' REPLY: We regret that the use of the terms 'arthritis' and 'osteoarthritis' appear to have been used interchangeably in our recent paper. We can assure Drs Dequeker and Westhovens that we gave careful thought to the use of these two terms. We tried to use the term 'osteoarthritis' whenever possible (particularly in the Introduction and Discussion sections of our paper). However, our data were based on self-reported joint symptoms; we did not ask subjects about osteoarthritis specifically. Thus we tried to use the term 'arthritis' whenever we were referring to the data from our study (particularly in the Results section and in the tables). We thought it would be misleading to readers if, for example, we wrote about 'self-reported osteoarthritis of the hip'.

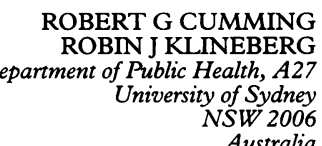

